\title{
NATURALLY PROPPED FRACTURES CAUSED BY QUARTZ CEMENTATION PRESERVE OIL RESERVOIRS IN BASEMENT ROCKS
}

MAS'UD.U. BABA ${ }^{1 *}$, JOHN PARNELL ${ }^{2}$, AND STEPHEN BOWDEN ${ }^{3}$

${ }^{1}$ CGG Robertson., Tyn Y Coed, Llanrhos, LL30 1SA, United Kingdom (*correspondence: Mas'ud.Baba@CGG.com) ${ }^{2}$ King's College, Aberdeen AB24 3FX (j.parnell@abdn.ac.uk) ${ }^{3}$ King's College, Aberdeen AB24 3FX (s.a.bowden@abdn.ac.uk)

Geochemistry of oils in fractured basement rocks Increasing interest in unconventional hydrocarbon resources includes a focus on the potential of fractured basement rocks. In light of the insufficient geochemical studies carried out on bitumen found in basement rocks across the United Kingdom, a molecular biomarker approach using thermal maturity, biodegradation and environment of deposition related biomarker compounds was used to study the small-scale hydrocarbon occurrence of bitumen in the fractured basement.

The assessment of a subsurface origin for biodegradation of bitumen found in basement rocks is based upon three approaches: petrography, organic geochemistry and thermal history. Petrographic studies show that bitumen was emplaced as a degraded solid rather than as low-viscosity oil. Organic biomarkers from the saturate fraction correlate the bitumen to their assumed oil bearing sedimentary source and also show that biodegradation occurred in the geological record and it is still ongoing. Biomarkers in coals, and fluid inclusions in mineral veins, constrain the levels of heating experienced by the rocks, and hence temperatures were suitable for microbial activity.

A fractured basement reservoir may be especially favourable as a subsurface habitat for microbes evinced by the biomarker data used in this study which offer an additional type of evidence for basement-hosted microbial activity

The case studies also show how oil can enter fractured reservoirs that were mineralized by hydrocarbon-bearing fluids where oil in the mineralizing fluid influenced the preservation of open fractures. When there is increasing interest in the detailed petrographic history of commercial fracture reservoirs, this study shows how oil can contribute to its own porosity. 